and 413 non-insulin dependent diabetics whose duration of diabetes ranged from 0.5 to 40 years. Urinary albumin was measured by rocket electrophoresis. For our normal range we measured albumin to creatinine ratios in 250 non-diabetic healthy volunteers (mean 0.75 (SD 0.93)). The upper limit of normal was defined as $2 \cdot 6$ (mean $+2 \mathrm{SD}$ ). Twenty per cent of the results obtained from insulin dependent diabetics and $25 \%$ of those from non-insulin dependent diabetics were positive. Interestingly $19 \%$ of both groups were found to be positive within two years of diagnosis. Repeat sampling on at least three occasions showed, however, that positive results were far from consistent. Results were considered to be true positives if there were three consecutive positive results; transient positives occurred when a positive result was followed by negative results. True negatives occurred when there were three negative results, and transient negatives occurred when there was a single negative result with at least two positive results. On this classification and assuming that the patients with true positive results represent those more likely to develop macroalbuminuria and renal failure, then $6.6 \%$ of insulin dependent diabetics and $13 \%$ of non-insulin dependent diabetics were at risk after two years. When true positive and transient negative results were combined then $13 \%$ and $23 \%$ respectively showed positive values.

These studies emphasise the high proportion of transient positive results $(21 \%$ in insulin dependent and $19 \%$ in non-insulin dependent diabetics), and we strongly recommend that at least three samples should be tested over several weeks to confirm truly positive microalbuminuria. Whether "transient" negative microalbuminuria is of any importance must remain more speculative.

JOAN METCALFe JOHN L DAY

Department of Pathology,
Ipswich Hospital,

Ipswich Hospital,
Ipswich IP4 5PD

\section{Collars and corsets}

SIR,-We are concerned at the implication in Dr G J Huston's article (23 January, p 276) that physiotherapy is a physical placebo in the treatment of neck problems, especially those resulting from road traffic accidents.

The main reference used by the author in coming to the conclusion that "soft collars may be a less expensive means of providing a physical placebo than physiotherapy" is concerned mainly with acute nerve root problems rather than those associated with road traffic accidents and was published 20 years ago. ${ }^{1}$

While a regimen of early treatment of whiplash injuries by ice and heat, Maitland mobilisations, and hourly exercises within pain limits as advocated by Mealy et al appears to be a more expensive option, their study showed a significantly greater improvement in cervical movement and decrease in intensity of pain at eight weeks. ${ }^{2}$

LINDA M VASEY

JOHN CLEAK Christine M Ellingworth

Physiotherapy Department,

Doncaster Royal Infirmary,

Doncaster DN2 5LT

1 British Association of Physical Medicine. Pain in the neck and arm: a multicentre trial of the effects of physiotherapy. $B$ Med F 1966;i:253-8.

2 Mealy K, Brennan H, Fenelon GCC. Early mobilisation of acut whiplash injuries. BrMed f 1986;292:656-7.

SIR,-DrG J Huston (23 January, p 276) concluded that collars and corsets acted as a less expensive physical placebo than physiotherapy, which itself is unstudied.

The references he used were rather out of date (1957 and 1966). I would refer him to more recent works, such as those of Mealy et al and of Kopp et al. ${ }^{1}$ Both of these papers, with others, refute the placebo effect of physiotherapy theory put forward by Dr Huston.

On the question of fitting corsets, this is frequently done by physiotherapists as there are often no orthotists available. It is a great pity that these outmoded statements are allowed to be perpetuated as they do nothing for the relationship between chartered physiotherapists and doctors.

RosaleEN LITTLE Professional affairs office

Chartered Society of Physiotherapy,

London WC1R 4ED

1 Kopp JR, Alexander AH, Turocy RH, et al. The use of lumbar extension in the evaluation and treatment of patients with acute herniated nucleus pulposus: a preliminary report. Clin Orthop 1986;202:211-8.

AUTHOR'S REPLY,-I am grateful for the opportunity to expand on a very brief article. The trial of treatment of neck and arm pain quoted in my review is large and has not been superseded. The predominantly female population described, who had pain in the neck, shoulder, and arm and were mostly aged between 40 and 60 years, is typical of the patients encountered in a rheumatology clinic and clearly a different population from the young predominantly male group attending an accident and emergency department after whiplash injury, as described by Mealy et al. This latter study, while it must be a great encouragement to physiotherapists to progress to further research, described two groups each given a number of treatments. It is impossible to tell whether home exercises (cheap) or manipulative physiotherapy (expensive) contributed to the improvement described in one of these groups. This study cannot therefore be used to support the application of manipulative physiotherapy in patients with non-traumatic neck pain.

I maintain that the cost effectiveness of manipulative physiotherapy in the treatment of neck pain remains an unstudied area.

I will be as delighted as every other physician when an effective treatment for neck pain is defined. Until then I must rely on explanation and encouragement with or without unproved and placebo therapies. I suspect that placebos currently used may perform relatively well if examined for improvement in quality of life per unit cost. I hope that the Chartered Society of Physiotherapy will be able in a few years to define effective treatments fo neck pain in different populations as a result of studies stimulated by its members. Such studies would do much for the relationship between chartered physiotherapists and doctors.

I am surprised that the greater part of fitting of corsets is performed by physiotherapists but grateful to Ms Little for this information, as I found it impossible to discover from the DHSS even the gross number of corsets fitted annually in Britain.

G J HustoN

Seacroft Hospital,

Leeds LS14 6UH

\section{Pancreatic cancer}

SIR,-Professor R C N Williamson (13 February, p 445) has highlighted the depressing realities of treating pancreatic cancer. The long term goals are elucidating the aetiology of the disease and refining diagnostic techniques to detect early lesions. Nevertheless, there are approaches that are worth exploring now.

Tamoxifen is unlikely to have an important impact on outcome. ${ }^{1}$ In contrast, there have been two recent and potentially important studies from the North American Gastrointestinal Tumour Study Group. In the first study 43 patients who had had resection of their cancers were randomised to a control group or a treatment group, which received two $2000 \mathrm{rad}(20 \mathrm{~Gy})$ courses of supervoltage radiation after surgery and fluorouracil weekly for two years. ${ }^{2}$ This regimen was repeated in a second cohort of 30 patients. $^{3}$ The two year survival was $43 \%$ and $46 \%$ respectively in these treated groups with a probable $20 \%$ five year survival. These results are superior to anything previously reported.

There may be even better regimens of potential value, but it is vital that the efficacy of this one is assessed. We are about to launch a national study of postoperative radiotherapy and fluorouracil coordinated by the West Midlands Cancer Research Campaign clinical trials unit. We would welcome the participation of all interested surgical and oncological units.

J P NEOPTOLEMOS G BLACKLEDGE D SPOONER

Department of Surgery

Dudley Road Hospital,

Birmingham B18 7QH

1 Crowson MC, Dorrell A, Rolfe EB, Fielding JWL. A phase II study to evaluate tamoxifen in pancreatic adenocarcinoma. Eur f Surg Oncol 1986;12:335-6.

2 Gastrointestinal Tumour Study Group. Adjuvant combined radiation and chemotherapy following curative resection. Arch Surg 1985;120:899-903.

3 Gastrointestinal Tumour Study Group. Further evidence of effective adjuvant combined radiation and chemotherapy following curative resection of pancreatic cancer. Cancer following curative

\section{Complications of erythema infectiosum in pregnancy}

SIR,-Dr P K Buxton (23 January, p 257) mentions that the main complication of rubella is congenital abnormalities in infants of women exposed to rubella during pregnancy. He then discusses erythema infectiosum or fifth disease, caused by parvovirus B19, which, he states, has no reported complications. This, however, is at variance with the experience of obstetricians and virologists. There is now extensive evidence that human parvovirus B19 infection is associated with spontaneous abortions in the first trimester, ${ }^{1}$ hydrops fetalis resulting in intrauterine death in the second trimester, ${ }^{2}$ and stillbirth at term. ${ }^{3}$

Parvovirus attacks the fetal haematopoietic system, destroying the host cell. The resulting haemolysis and leucoerythroblastic anaemia will cause cardiac failure, oedema, and ascites similar to those seen in severe rhesus disease and will result in intrauterine death. Maternal infection in pregnancy does not consistently produce fetal problems; the full extent of fetal infection is unknown, but it appears to complicate about one third of maternal infections during pregnancy. ${ }^{12}$ Like rubella and cytomegalovirus, subclinical maternal parvovirus infection does not exclude the possibility of intrauterine infection. Raised maternal serum $\alpha$ fetoprotein concentrations in the second trimester in pregnancies complicated by parvovirus infection may act as a marker of fetal infection and poor fetal prognosis in advance of ultrasonic detection of fetal hydrops. ${ }^{4}$ The fetal leucoerythroblastic anaemia can also be diagnosed by fetal blood sampling.

Parvovirus infection is also not without com- 